\title{
Estudio radiológico de la vía aérea central
}

\author{
Dr. José D. Arce Valenzuela
}

I Servicio Radiología e Imágenes. Clínica Santa María.

\section{INTRODUCCIÓN}

El espectro de patologías que comprometen la vía aérea central es diverso en la edad pediátrica y algunas de ellas, exclusivas de esta etapa de la vida. Su implicancia clínica es variada, representando en algunas situaciones amenazas vitales, que requieren de una rápida resolución $n^{(1,2,5-9)}$. El pequeño calibre de la vía aérea y su fácil colapsibilidad en lactantes y niños menores, son causas de una mayor respuesta sintomática ante eventos congénitos o adquiridos que la disminuyan. Revisaremos los hallazgos en imágenes de cuadros que comprometen la vía aérea central, no siendo motivo de esta revisión la región nasofaríngea, ni la pequeña vía aérea periférica.

\section{Embriología}

El surco laringotraqueal se forma en la parte ventral del intestino anterior durante la tercera semana. El crecimiento hacia caudal y la formación de pliegues laterales lo separan del esófago, completándose esta a la sexta semana. El endodermo del intestino anterior se diferenciara en epitelio y glándulas traqueobronquiales, además del epitelio pulmonar. La proliferación de células del mesénquima a partir de la cavidad celómica dará origen a músculo liso, cartílagos y tejido conectivo. El cartílago ya está presente en la decima semana de gestación. El extremo de la tráquea tiene un crecimiento asimétrico originando los bronquios derecho e izquierdo. La bifurcación traqueal se desplaza gradualmente, desde el cuello hasta su posición definitiva, a nivel de la cuarta vertebra torácica. El desarrollo relativamente separado de laringe y de las bifurcaciones bronquiales, junto al desarrollo pulmonar, hace posible que anomalías traqueales se acompañen de laringe normal. Es necesario considerar que el lumen laríngeo se forma por recanalización en la decima semana y el traqueobronquial parte primariamente como un tubo(3).

\section{Anatomía \\ La tráquea constituye un tubo para la conducción del aire, que comienza en el cuello a nivel del cartílago cricoides, pasa por detrás del manubrio esternal y sus puntos de referencia distal son; la cuarta a quinta vértebra dorsal o hacia anterior el ángulo esternal. En este punto se bifurca formando la carina y origina los bronquios fuentes. Está compuesta por 16 a 20 cartílagos con forma de herradura, que ocupan su porción anterolateral y por una pared membranosa en su parte pos- terior. Mide $4 \mathrm{~cm}$ de longitud en el recién nacido y $11-13 \mathrm{~cm}$}

Correspondencia: José D. Arce Valenzuela

E-mail: jarce@csm.cl

ISSN 07 | 8-332| Derechos reservados. en el adulto. Su diámetro en tanto es de 3-4 mm en el RN y 12-23 mm en el adulto(4).

Dos impresiones extrínsecas son normales en la tráquea; una superior por los lóbulos tiroideos y otra inferior e izquierda por el arco aórtico, que produce un normal desplazamiento de la tráquea hacia la derecha. Se debe considerar que en el niño la laringe es más alta y la lengua relativamente más grande y que cambios importantes del diámetro y morfología traqueal ocurren durante la respiración particularmente en el lactante. Durante la espiración hay un desplazamiento lateral derecho de la tráquea a nivel del opérculo torácico alejándose del arco aórtico. Hay además un desplazamiento anterior aumentando el espacio retrofaríngeo y retrolaríngeo. También hay un desplazamiento anterior con la flexión cervical. La tráquea en su porción cervical extratorácica disminuye su calibre durante la espiración y lo aumenta en espiración, lo contrario ocurre en su parte principal intratorácica en donde aumenta su calibre en inspiración y lo disminuye durante la espiración $n^{(2)}$. Los tejidos blandos retrofaríngeos y laríngeos disminuyen progresivamente con la edad.

\section{Clínica}

Las manifestaciones clínicas que motivan el estudio imaginológico son principalmente estridor y sibilancias. A veces hay otros síntomas como: aleteo nasal, dificultad para la alimentación, taquipnea, retracción costal, hemoptisis, fiebre, retraso pondoestatural y dificultad respiratoria. En ocasiones la anomalía de la vía aérea puede ser asintomática y ser sólo un hallazgo en estudio de imagen. Las obstrucciones pueden ser intrínsecas o extrínsecas, intra o extratorácicas y fijas o dinámicas, estas circunstancias motivaran cual será el mejor estudio por imágenes.

\section{Estudio imaginológico}

Radiografía $(R x)$ de cuello y tórax (AP, L): Habitualmente es el primer estudio de imágenes, que en sus proyecciones convencionales puede orientar a un diagnostico definitivo 0 nuevos procedimientos para precisarlo.

Radioscopía (Cinefluoroscopia, Seriografía secuencial): En forma dinámica se puede documentar los cambios de calibre de la vía aérea. En forma especial se puede observar el colapso espiratorio en pacientes con traqueobroncomalacia. También es útil para demostrar el bamboleo mediastínico y la restricción de la motilidad diafragmática por retención aérea en presencia de un cuerpo extraño, o cualquier condición que determine obstrucción parcial de la vía aérea.

Estudio contrastado del esófago: Útil para determinar compresión extrínseca en particular las de tipo vascular.

Técnicas axiales: Son sin duda estas, sumadas a sus posibilidades de reformateo, las que serán más útiles para el estudio 

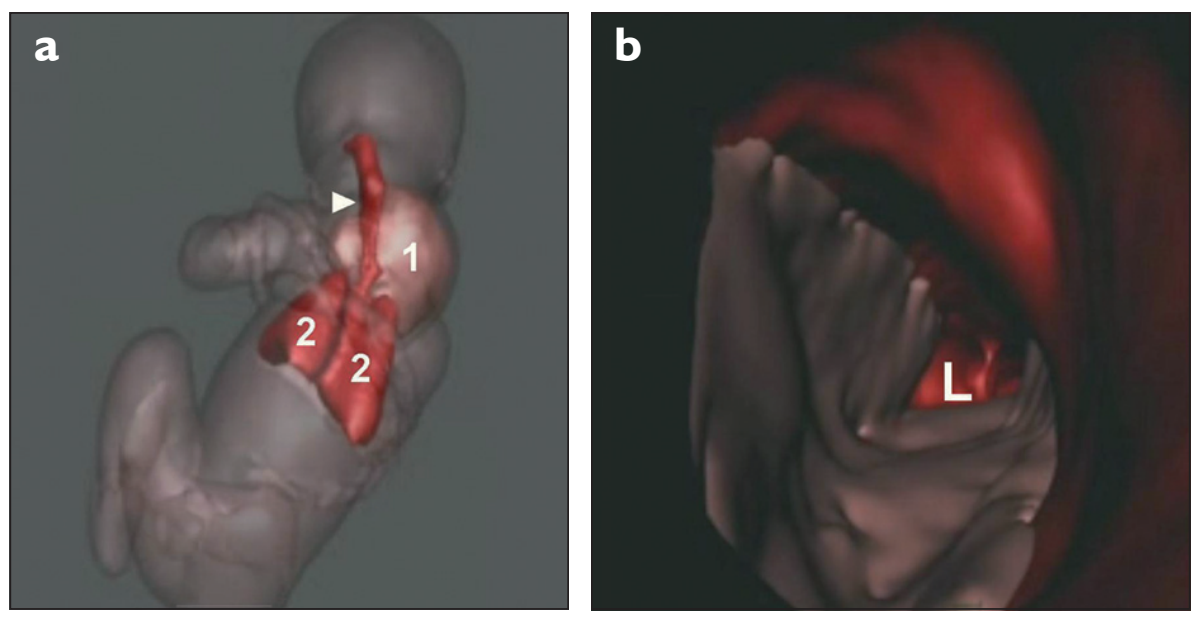

Figura I.

de vía aérea y su relación con masas o estructuras vasculares adyacentes, también en buena forma permiten un adecuado estudio del lumen.

La Tomografía Computada (TC) con sus posibilidades de estudio angiográfico y el post-proceso: multiplanar, volumétrico y endoscopia virtual dan un apropiado estudio anatómico; sin embargo es necesario considerar que a pesar de la rápida adquisición de la información necesaria, se expone al niño a radiación ionizante.

La Resonancia Magnética (RM) con similares posibilidades de información, precisa en niños largos tiempos de examen, siendo necesaria la sedación anestésica. Una gran utilidad de esta técnica es el estudio prenatal de obstrucción de la vía aérea superior la cual precisara de una rápida intervención al momento del parto(5) (Figura I).

\section{PATOLOGÍA LARÍNGEA}

\section{Hendiduras laríngeas}

Constituyen una rara patología con una incidencia probablemente subestimada. Las anomalías laríngeas ocurren entre I:2.000 a 1:50.000 nacidos vivos y las hendiduras laríngeas representan un 0,5 a I,6\% de este total. Presentan diferentes grados de extensión que pueden alcanzar hasta la tráquea. Las manifestaciones clínicas y el momento del diagnostico, dependerán de esta y se manifiestan como dificultad respiratoria y para la alimentación. Los niños pueden presentar llanto ronco, incapacidad para manejar secreciones, ahogos, estridor y cianosis. Un alto índice de sospecha evitara una aspiración pulmonar crónica. En un alto porcentaje se asocian a otras anomalías congénitas particularmente fistula traqueoesofágica y traqueomalacia ${ }^{(2,6)}$.

La radiografía de tórax mostrara en algunos casos signos sugerentes de un proceso aspirativo sin identificar la causa. A veces la proyección lateral puede mostrar desplazamiento anterior de una sonda nasogástrica. El estudio baritado mostrara un inmediato pasaje del contraste a la vía aérea (Figura 2 ), sin embargo, en algunos casos con aspiraciones menores es difícil precisar entre una alteración funcional y una pequeña hendidura(6).

\section{Epiglotitis}

Reportada en la literatura es poco frecuente y en nuestro medio, afecta a niños entre los 3 a 6 años durante el invierno. Asociada a infección por $H$. influenza tipo B, hoy los casos ocasionales son por infección por el tipo no B. Otros bacterias también pueden ocasionar epiglotitis. Simulan este cuadro la ingesta de alimentos calientes o alergia. Los pliegues ariepigloticos y la vía aérea subglótica pueden estar comprometidos.

En el estudio radiológico lateral de cuello se puede visualizar una epiglotis engrosada y redondeada o signo del dedo pulgar, con una subglotis normal.

\section{Laringotraqueitis "Croup"}

Compromete niños de 6 meses a 3 años durante los meses fríos. Relacionado a infección por virus parainfluenza. Curso clínico más benigno que la epiglotitis. Casos ocasionales pueden requerir intubación y producir edema pulmonar. El

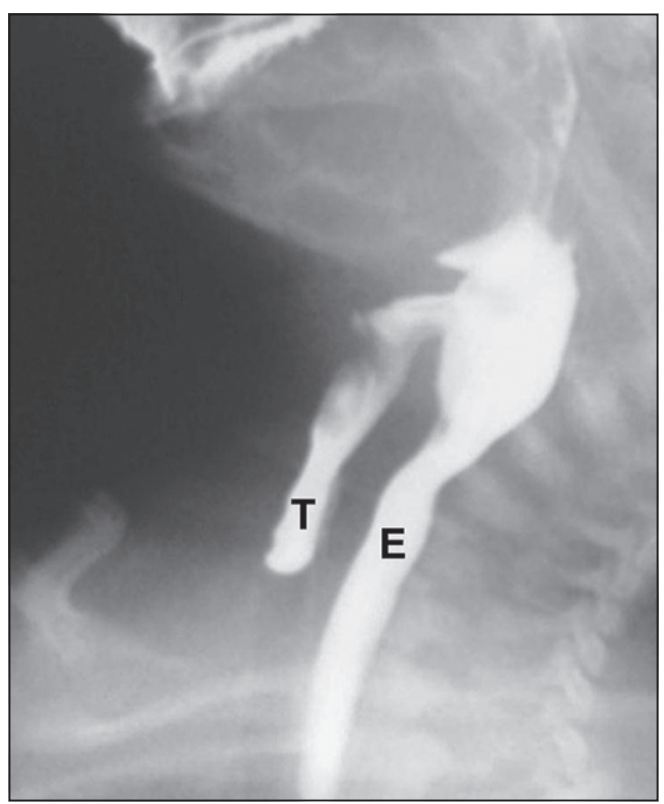

Figura 2. 


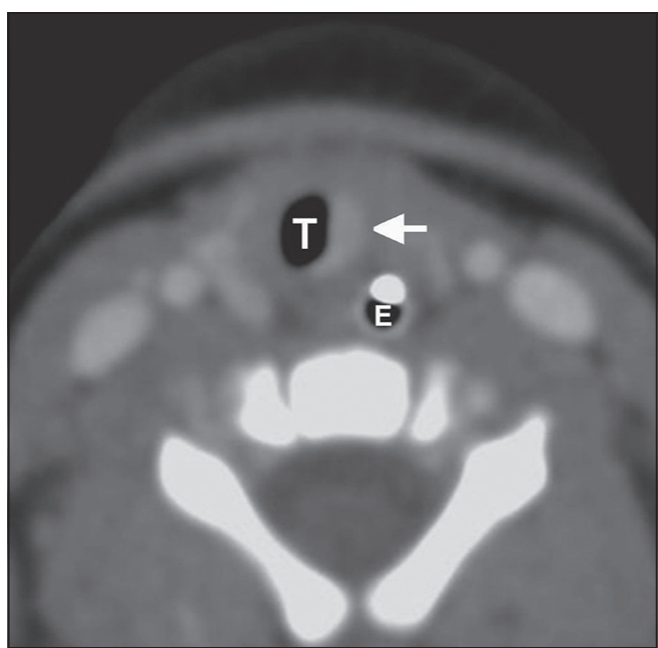

Figura 3.
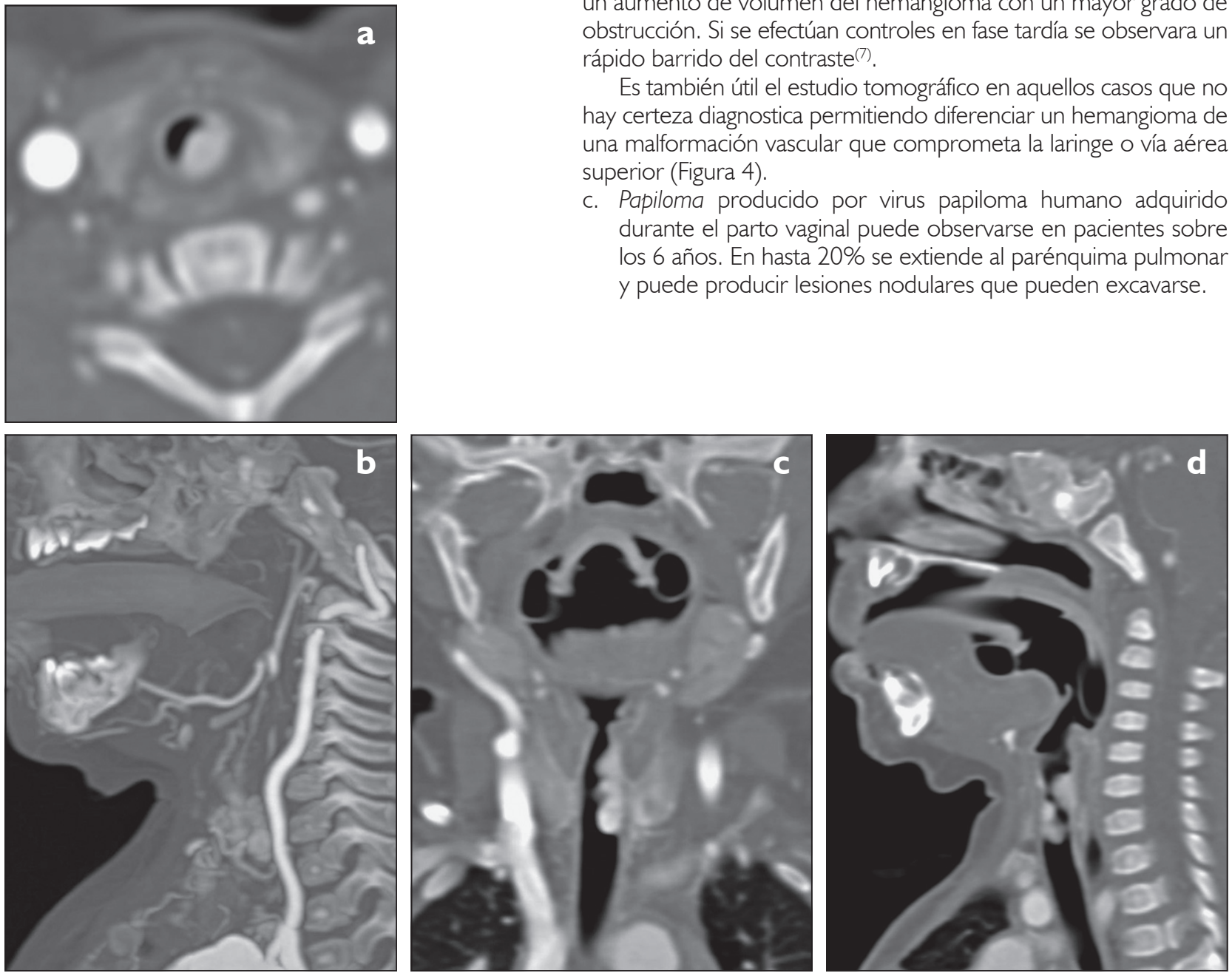

Figura 4. 


\section{PATOLOGÍA DE TRÁQUEA Y BRONQUIOS PRINCIPALES}

\section{Anomalías congénitas}

Diversas anomalías congénitas afectan la vía aérea discutiremos algunas excluyendo las que producen obstrucción total, como manifestación principal.

\section{Atresia esofágica con fistula y fístula en " $H$ " o en " $N$ "}

Esta anomalía derivaría de una alteración en la separación del intestino anterior con el brote traqueal primario, dentro del espectro de anomalías la más frecuente es la atresia esofágica, con fistula traqueoesofágica al cabo distal del esófago, con una frecuencia de $80-90 \%$ de los casos. La fistula aislada es más rara ocurriendo en un 5-8\% de los casos. El cuadro clínico se puede manifestar como un polihidroamnios prenatal, el acumulo de secreciones en el postnatal, imposibilidad al pasaje de una sonda o dificultad respiratoria.

La Rx simple de tórax especialmente la proyección lateral demostrara una imagen aérea sacular, en la región retrotraqueal que termina en fondo un ciego, produciendo diferentes grados de compresión y desplazamiento de la tráquea. La presencia de fistula es fácil de reconocer observando la presencia o ausencia de aire bajo el diafragma en estomago o asas intestinales (Figura 5 a y b). La presencia de una fistula aislada requiere de un alto índice de sospecha. En estos casos la administración de una pequeña cantidad de bario, con el paciente girando la cabeza y quedando en una posición levemente oblicua, lo demostrara en la mayoría de los casos (Figura $5 \mathrm{c}$ ).

\section{Fístula broncobiliar}

Extremadamente rara se manifiesta como tos o neumonía que no responde a tratamiento o como neumonías recurrentes, dificultad respiratoria y retardo en el desarrollo pondoestatural que comienzan en el período neonatal. La presencia de secreciones teñidas de bilis orientan a su diagnóstico. Descrita por Neuhauser en 1952 comunican el lóbulo izquierdo del hígado con el árbol traqueobronquial. Pueden comunicar con la, tráquea, carina o el bronquio fuente. Todas las fístulas pasan por el hiato esofágico. La gravedad de los síntomas depende de la cuantía de bilis drenada al pulmón, pudiendo efectuarse todo el drenaje hacia este. En Rx de tórax se observa ocupación del espacio aéreo, con consolidación variable. El hallazgo de aire en vesícula o vía biliar debe orientar al diagnostico. La TC demostrara la presencia de una estructura tubular accesoria próxima a la carina y con un curso descendente paralelo al esófago. El reformateo multiplanar o 3D demostrarán claramente el trayecto fistuloso(l,8) (Figura 6).

\section{Anomalías de segmentación bronquial y divertículo traqueal}

El divertículo traqueal y el bronquio cardiaco tienen en común ser formaciones saculares que se originan en la vía
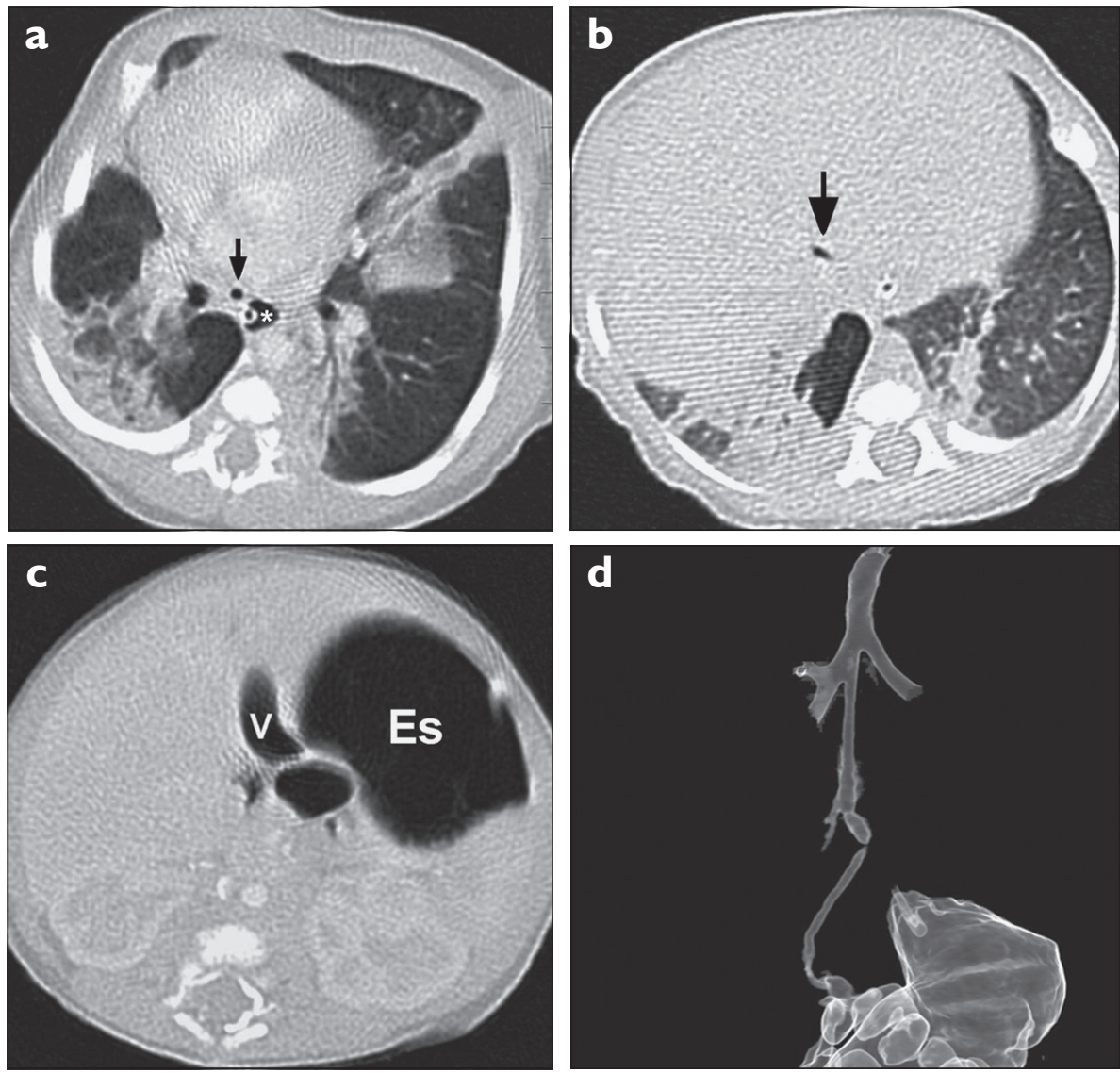

Figura 5. 

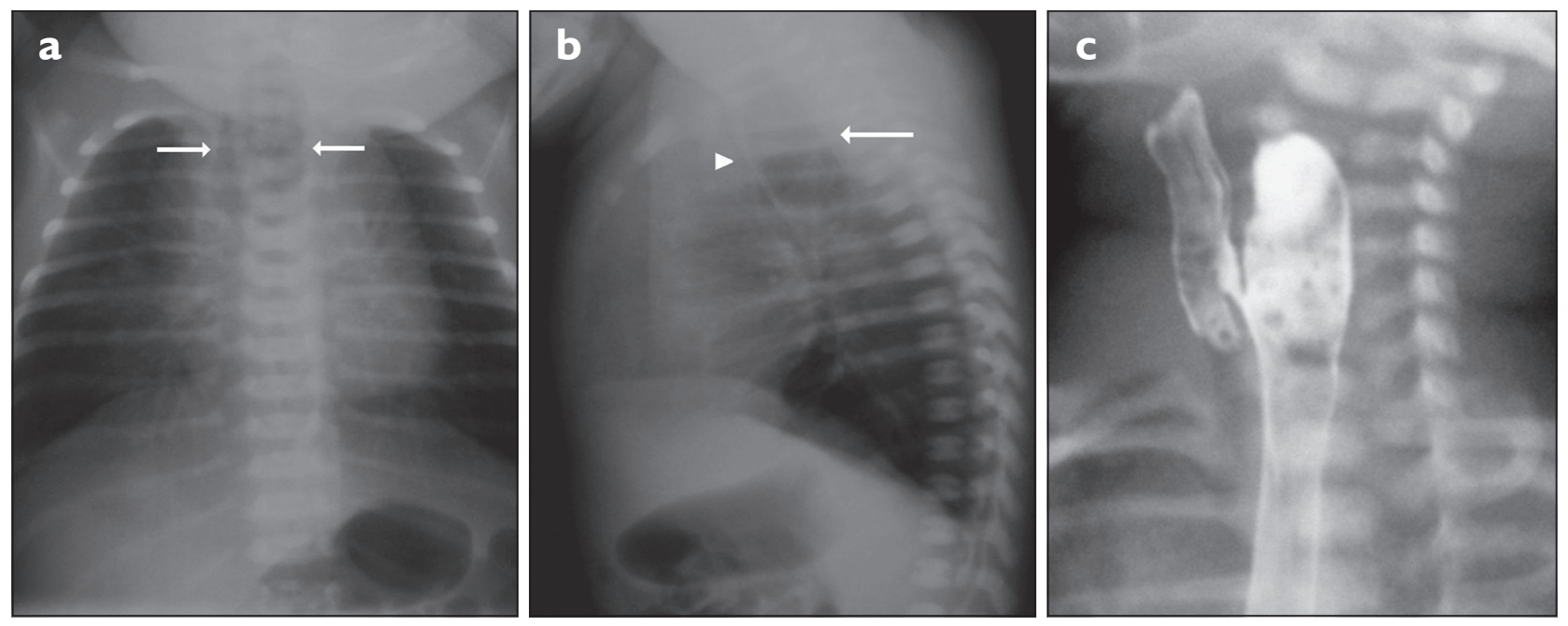

Figura 6.

aérea, difieren en su ubicación y origen. Están recubiertos de mucosa bronquial normal y poseen cartílago en su pared a excepción del traqueocele. El divertículo traqueal es una rara anomalía descrita en 1838, está presente en necropsias en menos del $1 \%$ de la población; puede ser congénito o adquirido (traqueocele), único o múltiple. La forma congénita es considerada un brote anómalo de la tráquea con pared completa, generalmente ubicado a derecha. La adquirida o traqueocele, sólo está formada por mucosa Más frecuente en hombres generalmente asintomáticos, pero en algunos caso se ha reportado tos crónica, apnea, parálisis del nervio laríngeo recurrente y atelectasia ${ }^{(9)}$ (Figura 7).

El bronquio cardiaco es considerado un bronquio supernumerario que nace de la pared inferomedial del bronquio principal derecho o intermedio y se dirige hacia el pericardio. En algunos casos se pueden ramificar y terminar en tejido parenquimatoso bronquiolar vestigial, degeneración quística o en un lóbulo con espacio aéreo ${ }^{(10)}$. Estas anomalías son generalmente asintomáticas y son hallazgos incidentales, podrían ser un potencial reservorio de agentes infecciosos con eventual hemorragia, tos o neumonía recurrente.

El bronquio traqueal originalmente descrito como un bronquio para el lóbulo superior derecho, nace directamente desde la pared lateral derecha de la tráquea, incluye además cualquier bronquio anómalo que se origine de tráquea o bronquio y se dirija el lóbulo superior. Tiene una prevalencia de 0,1 a $2 \%$. Hay una forma menos común de bronquio traqueal izquierdo. Generalmente son hallazgos y deben ser considerados en un paciente intubado con atelectasia persistente del lóbulo superior(2) (Figura 8a). El bronquio puente considera el origen del bronquio para el lóbulo inferior derecho desde el bronquio fuente izquierdo y se asocia generalmente a cardiopatía congénita (Figura 8b).

Otras: Agenesia/atresia bronquial por sus implicancias no compatible con la vida.

Hay varias anomalías menos comunes entre ellas ausencia o anomalías de los cartílagos, duplicación traqueal, hipoplasia $\mathrm{o}$ atresia bronquial.

\section{Obstrucción de la vía aérea}

Se la puede clasificar de diferentes forma ya sea considerando su causa primaria, la alteración funcional producida, la ubicación en relación a la pared o lumen y su ubicación anatómica.

Congénita/Adquirida (Inflamatoria, Infecciosa, Traumática, Neoplásica)

Fija/Dinámica

Intrínseca (parietal o intraluminal) / Extrínseca

Intratorácica / Extratorácica

Para fines prácticos las analizaremos desde la relación de la causa con la pared.
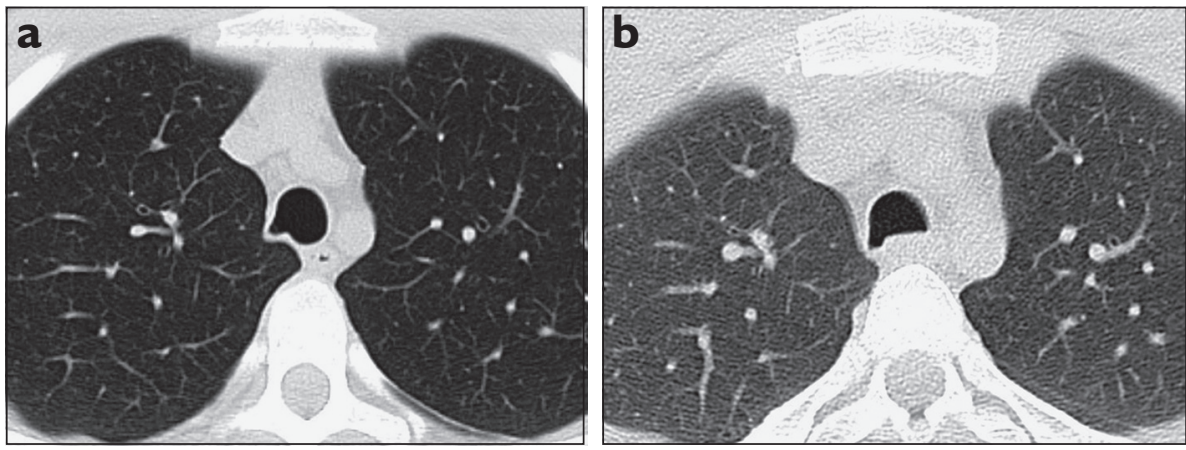

Figura 7. 

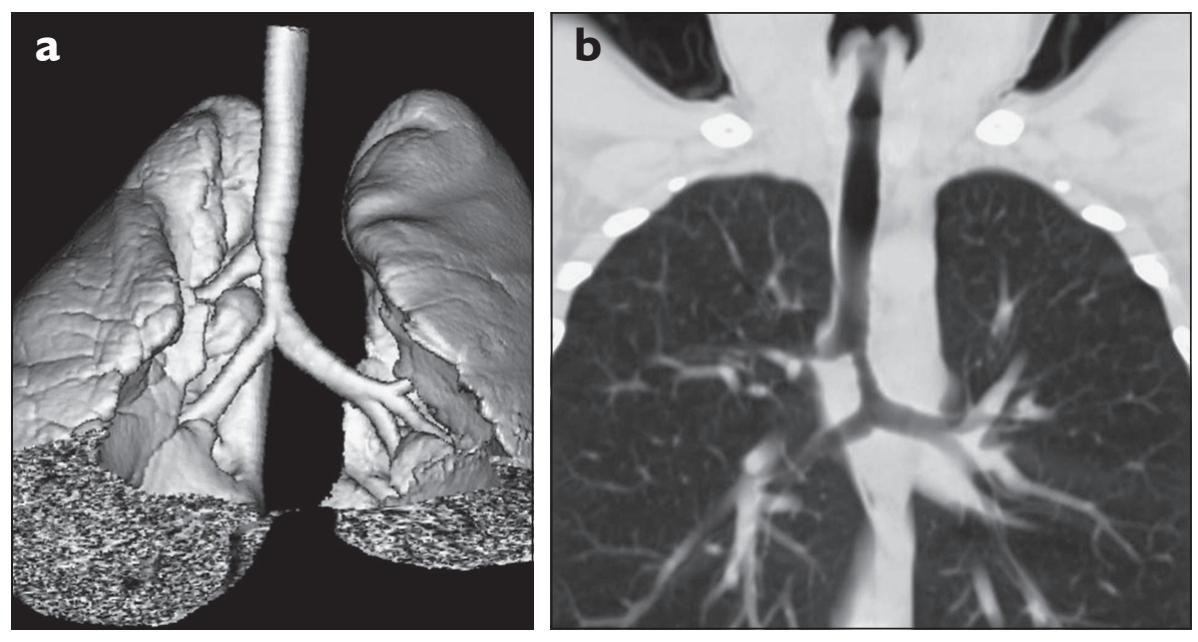

Figura 8.
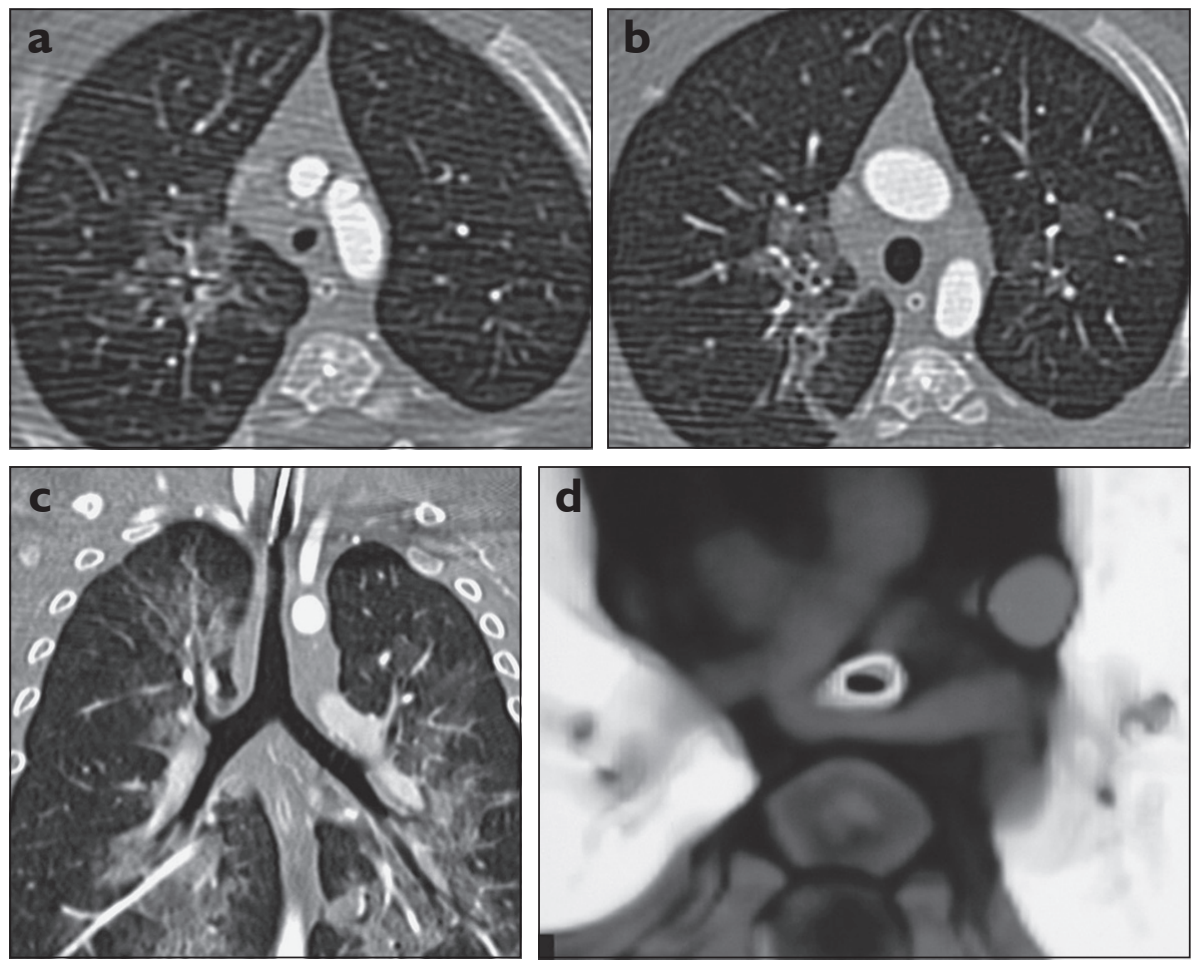

Figura 9.

\section{2a. Obstrucción de la vía aérea intrínseca 2al. Alteraciones de la pared: \\ Estenosis traqueobronquial congénita}

Se han considerado dos grupos de estenosis; uno formado por alteración fibromenbranosa, entre las cuales se consideran las asociadas con atresia y fistulas esofagotraqueales, las membranas y las estrecheces fibrosas. Un segundo grupo corresponde a alteraciones del cartílago entre las cuales están la traqueomalacia, ausencia, defectos de formación o alteraciones morfológicas del cartílago y las alteraciones secundarias o que acompañan a los anillos o compresión vascular. La estenosis traqueal o bronquial congénita con anillos completos, generalmente acompaña otras anomalías, en más de la mitad de los casos generalmente cardiaca o pulmonar (Figura 9). La estenosis de la vía aérea está muy asociada a la cuerda pulmonar o origen anómalo de la arteria pulmonar izquierda, generalmente hay anillos cartilaginosos completos los cuales deben ser cuidadosamente explorados (Figura 9d). La repercusión fisiológica de la estenosis estará determinada más por la disminución del calibre que por su extensión ${ }^{(2)}$.

\section{Traqueobroncomalacia}

Puede ser primaria o secundaria y es la causa más común de colapso y obstrucción de la vía aérea en el paciente pediátrico. En la mayoría de los casos es una condición autolimitada a los dos primeros años de la vida. Raramente ocurre como condición aislada por patología del cartílago. Comúnmente 
asociada a otras anomalías congénitas, particularmente atresia esofágica y fistula traqueoesofágica. También se puede asociar a compresiones vasculares y masas de partes blandas. Hay una alteración en el desarrollo del cartílago, probablemente facilitado en el caso de la atresia esofágica por la dilatación y compresión del segmento de esófago dilatado. De igual forma ocurre una alteración del desarrollo cartilaginoso, ante cualquier causa que produzca una compresión extrínseca. Cualquiera sea la causa se produce una alteración en la relación porción cartilaginosa-membranosa de la vía aérea en favor de esta última. Los síntomas aun cuando pueden presentarse al nacimiento, se manifiestan más comúnmente a los dos meses. Se caracterizan por estridor y tos metálica. Hay también dificultad respiratoria durante la alimentación y cuadros infecciosos recurrentes.

Normalmente la vía aérea mantiene su lumen durante la espiración por su componente cartilaginoso, sin embargo un aumento en la colapsibilidad de este y el aumento de la presión intratorácica hacen que disminuya su calibre en sentido anteroposterior, lo cual se agrava con la tos o maniobras de Valsalva. El estudio por imágenes debe efectuarse por tanto en proyección lateral empleando técnicas con serie rápida o de cine (Figura 10). Es necesario además considerar que la normal presión de la aorta por delante y del esófago por posterior, se agrega en casos de fistula traqueoesofágica una menor presión en el lumen traqueal $\left.\right|^{(1,2,1)}$.

\section{Membranas}

Comprenden una rara anomalía congénita de difícil diagnostico generalmente tratadas como asma o enfermedad pulmonar crónica obstructiva. Para que la disnea se haga clínicamente aparente debe comprometer aproximadamente un $75 \%$ de lumen traqueal. Después de cirugía para fistula esofagotraqueal también pueden formarse pliegues mucosos que pueden ser confundidos en exámenes endoscópicos como fistulas. El estudio con TC demostrara tanto el pliegue como la continuidad de la pared. El estudio baritado de esófago puede también demostrar alteraciones mucosas ${ }^{(12)}$ (Figura I I).

\section{Tumores}

Los tumores que afectan las glándulas traqueobronquiales son el carcinoma mucoepidermoide, tumor carcinoide bronquial y carcinoma quístico adenoideo o cilíndrico, siendo el más frecuente en niños el carcinoide, que es además el principal tumor pulmonar primario a esta edad.

\section{Carcinoide bronquial}

Tumor neuroendocrino, primariamente considerado como adenoma bronquial, sin embargo, no es uniformemente glandular ni absolutamente benigno. En niños raramente se manifiesta como síndrome carcinoide, excepto cuando da metástasis hepáticas. Comúnmente en bronquio lobar (75\%), menos frecuentemente en bronquio fuente (10\%) o parénquima pulmonar, (15\%). Compromete la pared y se extiende hacia el lumen y tejidos peribronquiales. Se manifiesta como atelectasia persistente en $\mathrm{Rx}$ de tórax (Figura 12 a,b); y el diagnóstico se realiza en estudio endoscópico en el curso de una pesquisa por posible cuerpo extraño.

En TC se manifiesta como una masa ovoidea, endobronquial, que puede obliterar el lumen bronquial parcial o totalmente, es bien vascularizado impregnándose con el contraste endovenoso (Figura $12 \mathrm{c}-\mathrm{g}$ ). A veces el componente endobronquial es relativamente pequeño con respecto al volumen tumoral total. Muchas veces resulta dificultoso determinar la real extensión del tumor dado el gran componente extrabronquial, y se puede asociar una masa hiliar. La presentación como nódulo pulmonar solitario es poco frecuente. Otros hallazgos tomográficos son condensación,
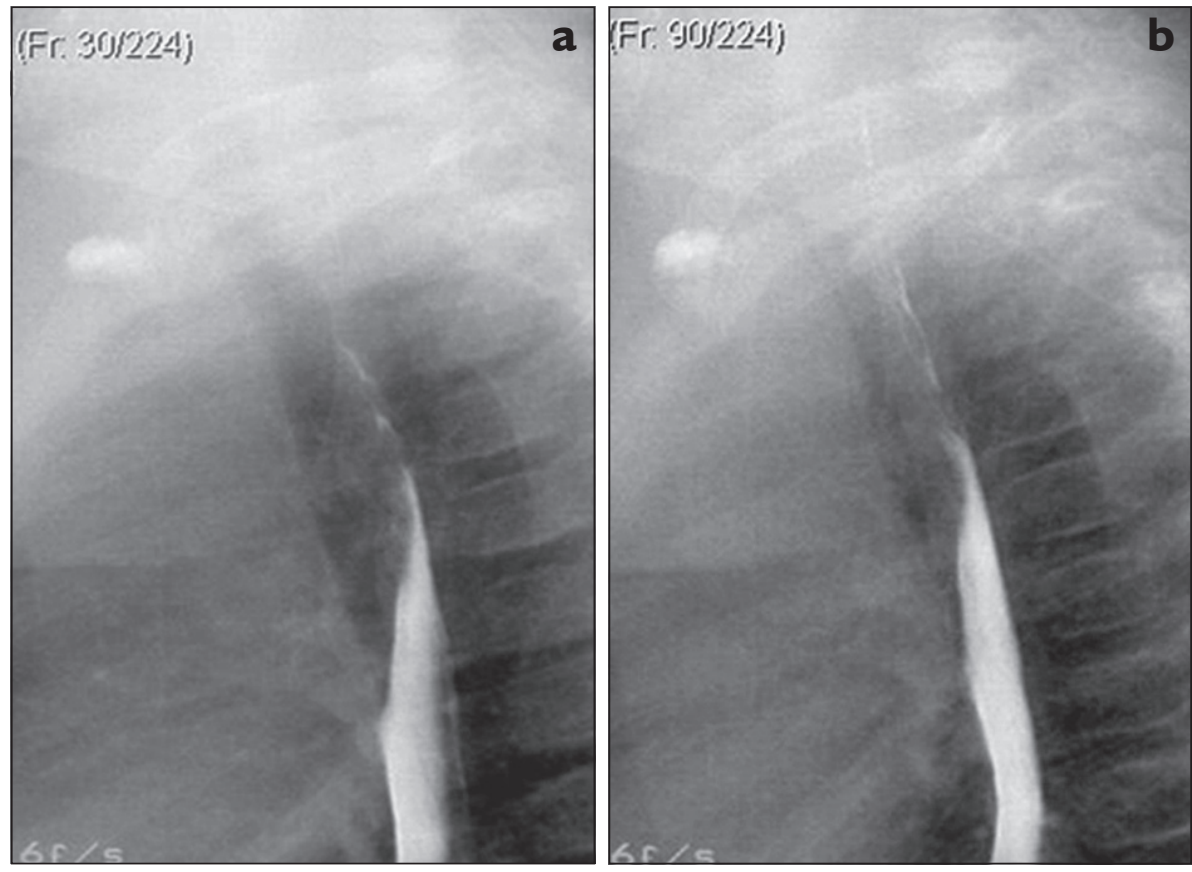

Figura 10. 

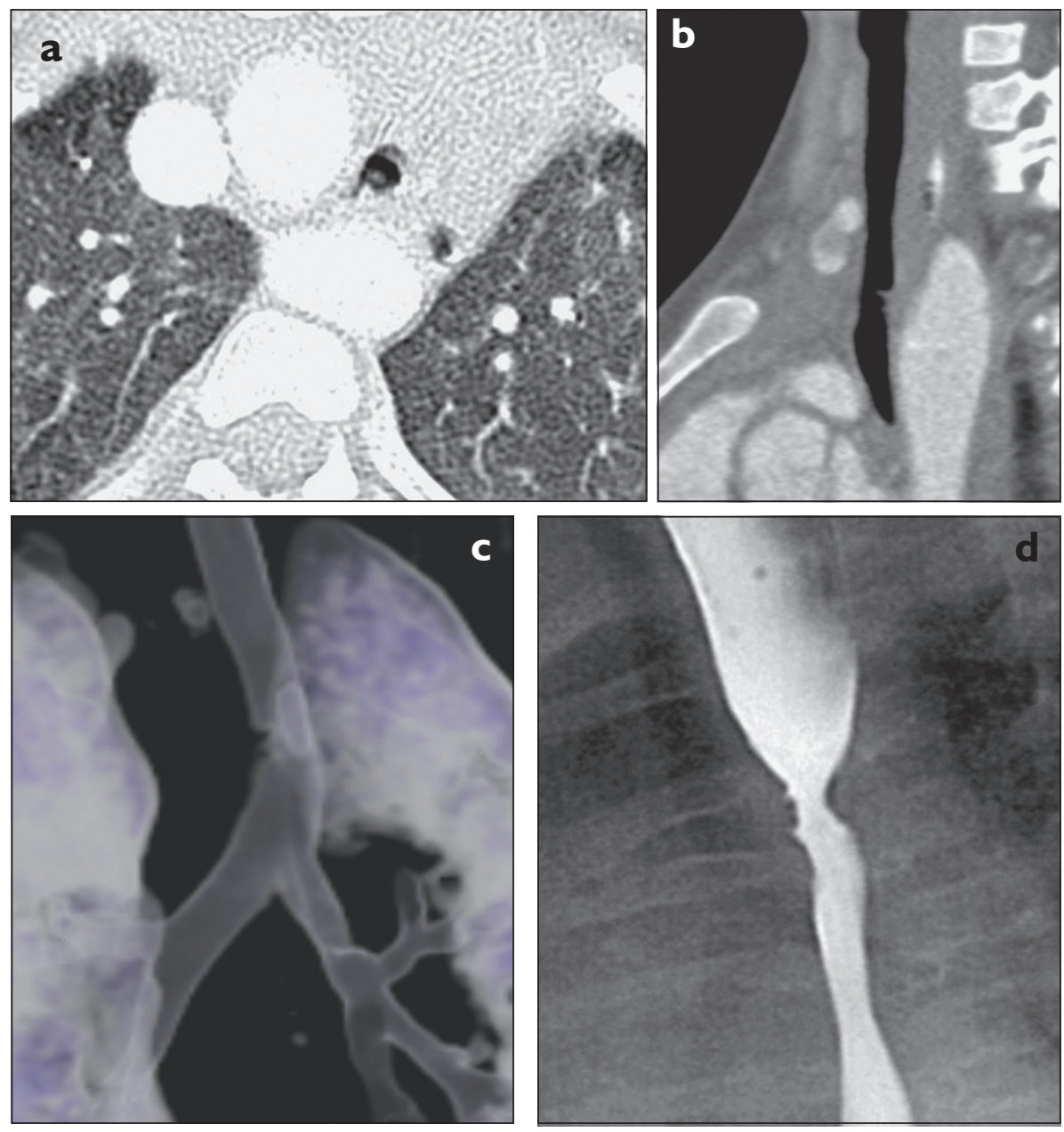

Figura II.

atelectasia, atrapamiento aéreo, y mucocele. Raramente se observan calcificaciones, a diferencia de los adultos. La incidencia de metástasis puede ser del 5 a $20 \%$ de los casos por diseminación linfática. Según los reportes en pediatría la resección quirúrgica es el mejor tratamiento y la sobrevida es del $90 \%{ }^{(13)}$

\section{2a2. Alteraciones intraluminales Cuerpo extraño traqueal}

En laringe o tráquea la aspiración de un cuerpo extraño que permanezca en ellas, puede manifestarse en forma aguda con grave dificultad respiratoria, estridor e incluso apnea, lo que imposibilitara la obtención de imágenes. Aun cuando poco frecuente la obstrucción total no resuelta rápidamente, producirá la muerte por asfixia. En otros casos el cuerpo extraño puede quedar atascado o moverse libremente entre la glotis y la carina. No hay disfonía; pero se presenta una tos persistente. Los cuerpos extraños subglóticos, durante el ciclo respiratorio, chocan con la glotis provocando un ruido característico, conocido como "papirotazo". La radiografía es especialmente útil en cuerpos radiopacos; sin embargo una cuidadosa observación puede identificar en proyección lateral, los no opacos por la diferencia de densidad de estos, con el aire de la vía aérea (Figura 13). En algunos casos la obstrucción disminuye la presión negativa intratorácica, manifestándose en $\mathrm{Rx}$ de tórax como una alteración simétrica de la aireación pulmonar y como una prominencia cardiomediastínica. La TC puede ser de gran utilidad en algunas condiciones.

\section{Cuerpo extraño bronquial}

Se observan especialmente en niños entre 6 meses y 3 años de vida, aun cuando también pueden ocurrir en niños mayores. En ausencia de un episodio asfíctico conocido, el diagnostico no resulta fácil. Los síntomas respiratorios pueden ser de corta duración, debido a una rápida pérdida de reacción de los receptores endobronquiales, de esta forma pueden permanecer en la vía aérea por períodos prolongados, con neumonías de repetición o presencia de sibilancias, que pueden ser confundidas con asma.

En lactantes y niños menores el ángulo traqueobronquial es similar en ambos lados, aspecto dado por un tórax más corto, en niños mayores las características anatómicas del bronquio fuente derecho facilitan que la aspiración sea más frecuente a este lado. Los hallazgos radiológicos dependerán de la localización y del tipo de cuerpo extraño. En su gran mayoría son de origen vegetal. La sensibilidad de Rx de tórax para pesquisarlos es variable al igual que su especificidad. La TC con una muy buena sensibilidad, se debe reservar para 

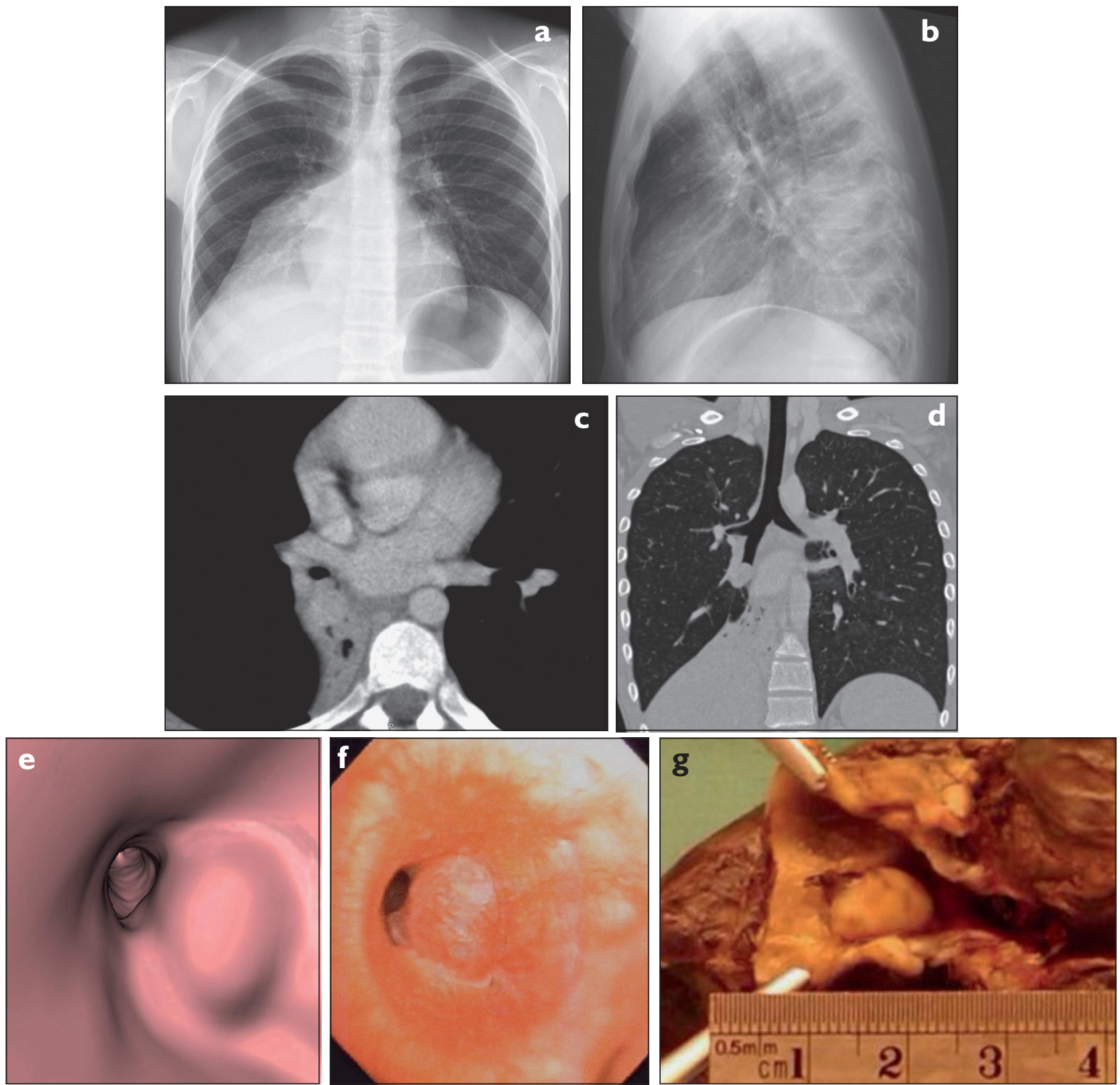

Figura 12.

casos de duda diagnóstica, por su dosis de radiación. Algunos prefieren ante la existencia de un alto índice de sospecha la realización directa de un estudio endoscópico.

La mayor parte de los cuerpos extraños se localizan en bronquios o en sus ramas principales; como son generalmente radiolúcidos, no son visualizados directamente y su diagnóstico estará dado por signos indirectos. En caso de obstrucción parcial se produce un mecanismo valvular con atrapamiento aéreo durante la espiración, observándose una alteración localizada de la transparencia del parénquima pulmonar. La extensión de este hallazgo dependerá del bronquio comprometido. Se produce además en forma secundaria una disminución de la vascularización del pulmón afectado. (Figura 14). En aquellos casos que se produce una obstrucción total primaria o por fenómenos inflamatorios secundarios se puede observar atelectasias, neumonías a repetición y bronquiectasias en aquellos de larga permanencia. En TC se puede visualizar directamente el cuerpo extraño independiente de sus características ${ }^{(14)}$.

\section{2b. Obstrucción de la vía aérea extrínseca 2bl. Compresión vascular}

En general la compresión de la vía aérea por estructuras vasculares, estará determinada por: una alteración embriológica del desarrollo vascular, crecimiento de estructuras vasculares normalmente desarrolladas o por alguna situación que altere la normal relación entre las estructuras vasculares y vía aérea. (Figura | 5). 


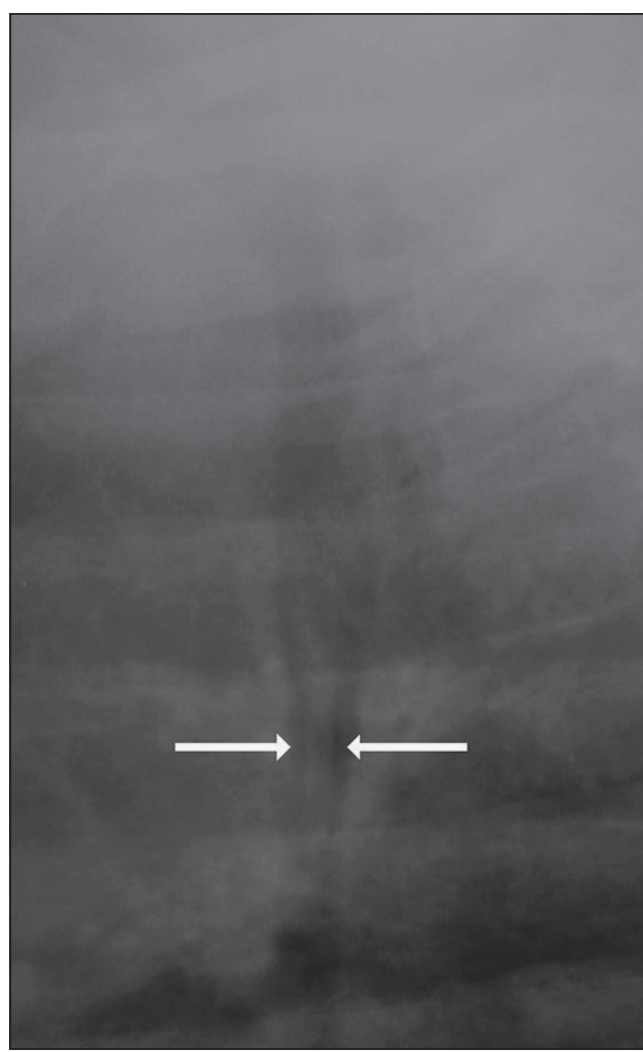

Figura 13.
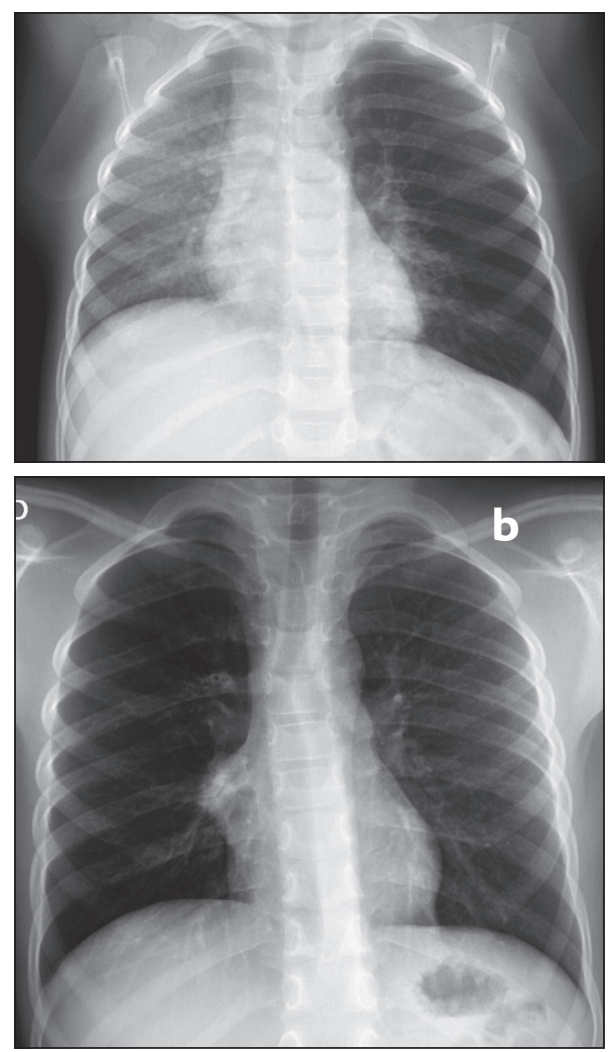

Figura 14.
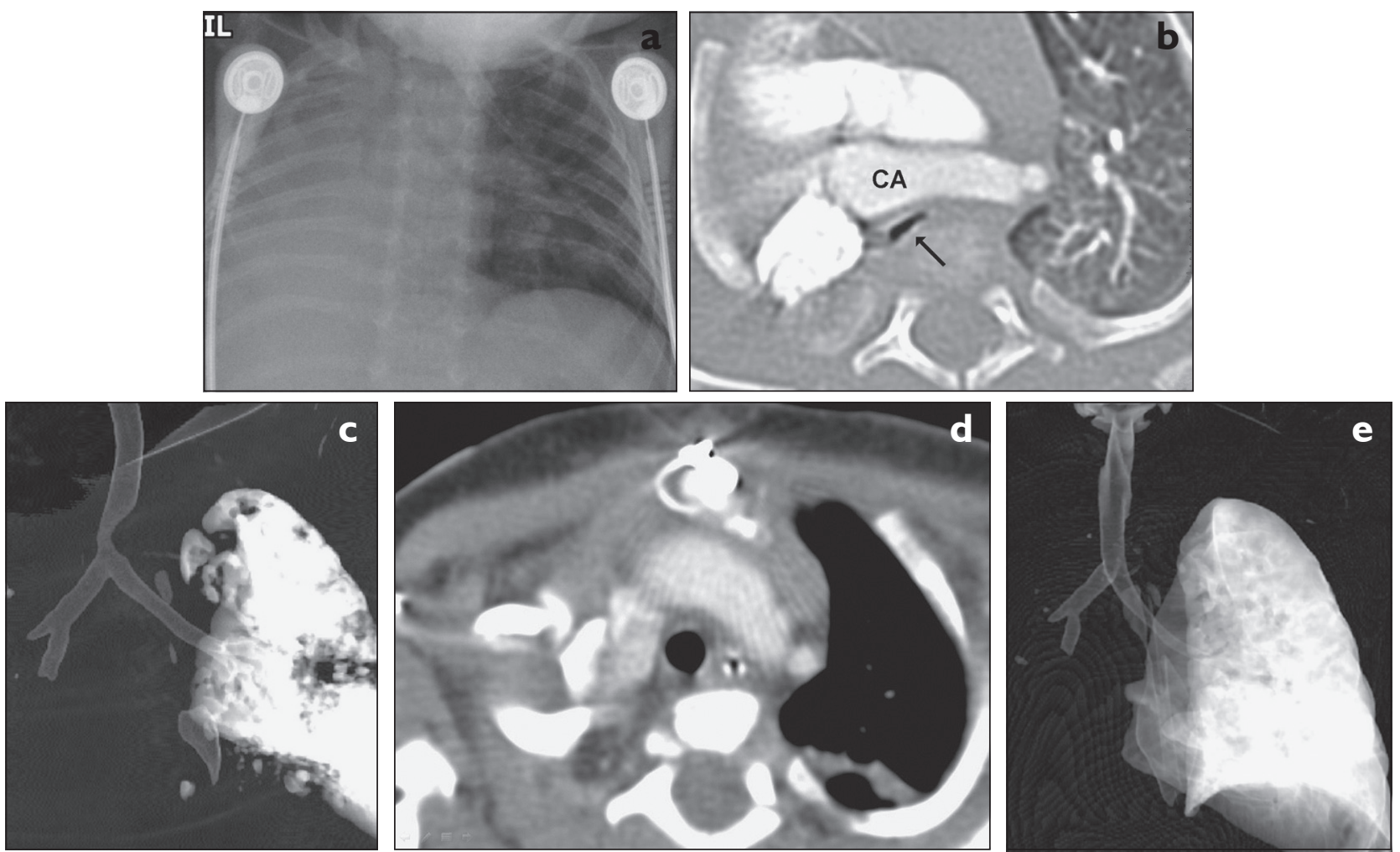

Figura 15. 
Causas conocidas son los anillos vasculares, la ausencia de la válvula pulmonar, miocardiopatía dilatada, la arteria pulmonar izquierda aberrante y la compresión por la arteria innominada; sin embargo cualquier estructura vascular desplazada o mal posicionada puede producir algún grado de compresión y disminución del calibre de la columna aérea, fácilmente colapsable en el niño menor. De igual forma algunas cirugías correctoras de cardiopatías congénitas podrían alterar la relación vasos con la vía aérea ${ }^{(15,16)}$. Es necesario considerar que la arteria innominada, normalmente cruza la pared anterior de la tráquea, contactándola en un 30\% de menores de 2 años sin producir compresión significativa o síntomas. Los síntomas además de estridor, pueden incluir disfagia, infecciones respiratorias recurrentes o episodios de apnea. Aun cuando las nuevas técnicas axiales de imagen con estudio angiográfico, son las técnicas de elección, la Rx de tórax con contraste esofágico permitirán muchas veces orientar el diagnostico al demostrar compresiones anómalas de la tráquea o esófago.

Aun cuando la TC utiliza radiación ionizante es en nuestra práctica la técnica de elección, considerando los riesgos de una anestesia prolongada en un niño con la vía aérea comprometida.

\section{2b2. Compresión extrínseca no vascular (l)}

Los cuerpos extraños esofágicos, al permanecer por largos períodos, producen inflamación y edema de la pared del esófago comprimiendo la vía aérea adyacente. También pueden perforar y producir compromiso inflamatorio con mediastinitis y obstrucción secundaria. Las anomalías derivadas del intestino anterior pueden producir distintos grados de compresión de la vía aérea, siendo los más frecuentes, los quistes broncogénicos que constituyen la lesión quística más común del tórax. Pueden estar situados en cualquier lugar, pero la posición subcarinal es frecuente. Otros quistes de origen común son los neurentéricos y los de duplicación esofágica. Los linfonódulos tumorales o inflamatorios también pueden comprimir la vía aérea. Cuando el compromiso es inflamatorio, se puede además afectar directamente la pared bronquial.

\section{Enfermedad crónica de la vía aérea o disquinesia ciliar}

La disquinesia ciliar primaria es causada por un defecto en la estructura y función ciliar que produce anomalías en su motilidad resultando una enfermedad sinusal y pulmonar. Se puede asociar a anomalías de la simetría toracoabdominal, en 50\% de los pacientes constituyendo la triada de Kartagener. Autosómica recesiva con una prevalencia de 1:12.000 a 1:60.000, se asocia también a infertilidad masculina. La morbilidad está asociada a enfermedad supurativa de la vía aérea secundaria a infección crónica con una progresión más lenta que la fibrosis quística. Las bronquiectasias están presentes en todos los adultos afectados y sólo en un $56 \%$ de los niños y es el lóbulo medio es el más afectado en ambas poblaciones. Rara en los lóbulos superiores (Figura 16).

\section{CONCLUSIONES}

La actual disponibilidad de métodos de imagen permite un adecuado estudio de la vía aérea central e intrapulmonar. Además del estudio intraluminal permiten las técnicas de imagen, un buen estudio de las alteraciones de la pared y las compresiones extrínsecas. En casos de alteraciones dinámicas el estudio debe ser complementado con estudios dinámicos o técnicas de cine.
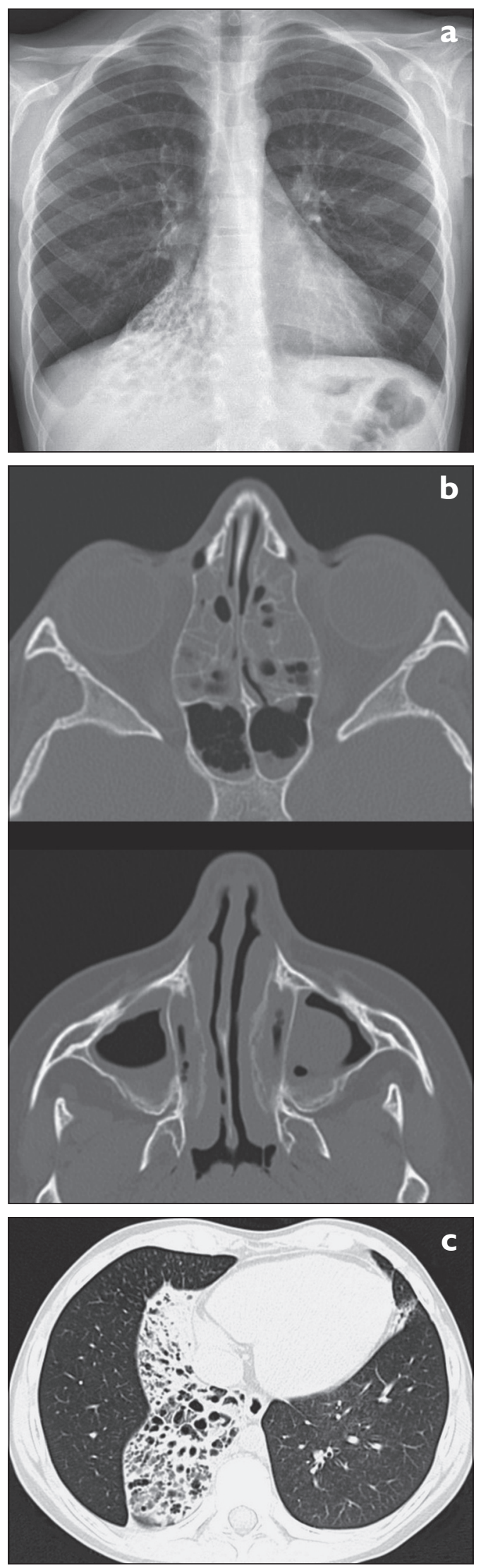

Figura 16. 


\section{REFERENCIAS}

I. Yedururi S, Guillerman RP, Chung T, Braverman RM, Dishop MK, Giannoni CM, et al. Multimodality Imaging of Tracheobronchial Disorders in Children. Radiographics 2008; 28: e29.

2. Kishore Sandu K, Philippe Monnier P. Congenital Tracheal Anomalies Otolaryngol Clin N Am 2007; 40: 193-217.

3. Skandalakis J, Gray S. Embriology for Surgeons. Baltimore, Ed. Williains \& Wilkins. 1994

4. Testut L, Latarjet A. Tratado de anatomía humana. Salvat editores 1973.

5. Courtier J, Poder L, Wang ZJ, Westphalen AC, Yeh BM, Coakley FV. Fetal tracheolaryngeal airway obstruction: prenatal evaluation by sonography and MRI. Pediatr Radiol 20 I0; 40: I800-5.

6. Pezzettigotta SM, Leboulanger N, Roger G, Denoyelle F, Garabédian EN. Laryngeal Cleft. Otolaryngol Clin N Am 2008; 41: 913-33.

7. Koplewitz BZ, Springer CH, Slasky BS, Avraham Avital A, Kammal Uwyyed K, Piccard E, et al. CT of Hemangiomas of the Upper Airways in Children. AJR 2005; 184: 663-70.

8. Chawla SC, Jha P, Breiman R, Farmer D, Gooding CH. Congenital tracheobiliary fistula diagnosed with contrast-enhanced CT and 3-D reformation. Pediatr Radiol 2008; 38: 999- 1002.

9. Restrepo S, Villamil MA, Rojas IC, Lemos DF, Echeverri S, Triana G, et al. Association of two respiratory congenital anomalies: tracheal diverticulum and cystic adenomatoid malformation of the lung. Pediatr Radiol 2004; 34: 263-6.

10. Derek Roebuck D, McLaren CA. Bronchus cardiacus accessorius dexter. Pediatr Radiol 20 10; 40: 1297.

II. Tan IZ, Ditchfield M, Freeze N. Tracheobronchomalacia in children: review of diagnosis and definition. Pediatr Radiol 2012; 42: 906- 15.

12. Legasto AC, Haller JO, Giusti RJ. Tracheal web. Pediatr Radiol 2004: 34: 256-8.

13. Chong S, Lee KS, Chung MJ, Han J, Kwon OJ,Kim TS. Neuroendocrine tumors of the lung: clinical, pathologic, and imaging findings. RadioGraphics 2006; 26: 4I-57.

14. Blazer S, Naveh Y, Friedman A. Foreign body in the airway: Review of 200 cases. Am J Dis Child 1980; 134: 68-7I.

15. McLaren CA, Elliott MJ, Derek J. Roebuck DJ. Vascular compression of the airway in children. Paediatr Respir Rev 2008; 9: 85-94.

16. Donnelly LF, Strife JL, Bailey WW. Extrinsic airway compression secondary to pulmonary arterial conduits: MR findings. Pediatr Radiol 1997; 27: 268-70.

17. Kennedy MP, Noone PG, Leigh MW, Zariwala MA, Minnix SL, Knowles MR, et al. High-Resolution CT of patients with primary ciliary dyskinesia. AJR 2007; I 88: 1232-8. 